\title{
PENYULUHAN MAKANAN SEHAT UNTUK PENCEGAHAN STUNTING BALITA
}

\section{HEALTHY FOOD COUNSELING FOR TODDLER STUNTING PREVENTION}

\author{
${ }^{1}$ Nining Lestari, ${ }^{2}$ Aulia Hanif \\ ${ }^{1}$ Staff Departemen Public Health and Family Medicine, Fakultas Kedokteran, Universitas \\ Muhammadiyah Surakarta \\ ${ }^{2}$ Mahasiswa Fakultas Kedokteran, Universitas Muhammadiyah Surakarta \\ Korespondensi: author 1. Alamat email: n1209@ums.ac.id
}

\begin{abstract}
ABSTRAK
Sasaran yang ingin dicapai Indonesia di bidang gizi adalah menurunkan prevalensi stunting menjadi $10 \%$ pada tahun 2030. Prevalensi stunting di Indonesia tahun 2018 masih tinggi yaitu 30,8\%, sehingga diperlukan upaya yang strategis untuk mencapai tujuan tersebut, salah satunya adalah dengan penyuluhan mengenai makanan sehat bagi ibu usia produktif sebagai sasaran primer dalam pencegahan stunting. Di TK Aisyiah Pucangan ditemukan balita usia 4-5 tahun yang mengalami stunting sebanyak 13 siswa dari 60 siswa pada kelompok usia tersebut, sehingga diperlukan upaya promosi kesehatan dengan melakukan penyuluhan. Tujuan jangka pendek penyuluhan adalah uutuk meningkatkan pengetahuan mengenai makanan sehat berigizi dan seimbang, sedangkan tujuan jangka panjang adalah untuk menurunkan kejadian stunting balita. Penyuluhan dilakukan dengan presentasi audiovisual menggunakan power point dan video edukasi. Untuk mengukur pengetahuan sebelum dan sesudah kegiatan maka digunakan "one group pre and post test design". Data yang didapatkan dianalisis dengan uji analisis Paired sample t test atau uji Wilcoxon menggunakan SPPS 22. Hasil analisis didapatkan rerata nilai pretest $=65,12$ dan post test $=82,2$. Hasil Uji Wilcoxon dari 41 responden didapatkan 36 responden mengalami peningkatan pengetahuan (nilai $p<0,0001$ ). Kesimpulan dari penelitian ini terdapat peningkatan pengetahuan setelah dilakukan penyuluhan tentang makanan sehat.
\end{abstract}

Kata Kunci: Makanan Sehat, Stunting, balita

\section{ABSTRACT}

The goal that Indonesia has to achieve in nutrition is to decrease the prevalence of stunting to $10 \%$ in 2030. The prevalence of stunting in Indonesia in 2018 is 30.8\%, so it takes strategic effort to achieve that goal by counseling about healthy food for mothers of productive age as the primary target in stunting prevention. In TK Aisyiah was discovered 13 students of 4-5 toddlers aged from 60 students in 4-5 years age group was stunting, so it took health promotion efforts by conducting counseling. The short-term goal of counseling is to increase the knowledge of healthy foods, while the long-term goal is to decrease the stunting of toddlers. Counseling was done with audiovisual presentations using power points and educational videos. To measure the knowledge, it is used "one group pre and post test design". The Data obtained was analyzed by Paired T Test or Wilcoxon test using SPPS 22. The average pretests value $=65.12$ and post test $=82.2$. Wilcoxon test results of 41 respondents gained 36 respondents experienced an increase in knowledge ( $p$ value of $<0,0001$ ). It is conclude that there is an increased knowledge after the healthy food counseling.

Keywords: Healthy food, Stunting, Toddlers 


\section{PENDAHULUAN}

Indonesia termasuk salah satu dari 17 negara dari 122 negara yang mempunyai 3 masalah gizi pada balita yaitu stunting, wasting dan gemuk (Achadi, 2015). Menurut data Riskesdes (Riset Kesehatan Dasar) tahun 2013 prevalensi stunting nasional mencapai 37,2 persen, meningkat dari tahun 2010 sebesar $35,6 \%$ dan 2007 sebesar 36,8\% (Riskesdas, 2013). Stunting didefinisikan sebagai kondisi anak usia $0-60$ bulan, dimana tinggi badan menurut umur berada di bawah minus 2 Standar Deviasi $(<-$ 2SD) dari standar median WHO (Kemenkes RI, 2011).

Pada tahun 2018 angka stunting turun menjadi 30,8 \%. Meskipun prevalensi stunting turun dari tahun sebelumnya tetapi Kementerian PPN/ Bappenas Indonesia mentargetkan pada tahun 2030 prevalensinya dapat turun menjadi $22,7 \%$ bahkan dengan intervensi khusus dapat diturunkan menjadi $10 \%$ pada tahun 2030 (Ministry of National Development Planning of Indonesia, 2019) .

Stunting pada balita merupakan faktor risiko meningkatnya angka kematian, menurunkan kemampuan kognitif dan perkembangan motorik rendah serta fungsi-fungsi tubuh yang tidak seimbang. stunting pada balita berhubungan dengan keterlambatan perkembangan bahasa dan motorik halus sedangkan stunting yang terjadi pada usia 36 bulan pertama biasanya disertai dengan efek jangka panjang (Hoffman, 2014).

Pencegahan stunting memerlukan intervensi gizi yang terpadu, mencakup intervensi gizi spesifik dan gizi sensitif. Pengalaman global menunjukkan bahwa penyelenggaraan intervensi terpadu yang melibatkan lintas sektor dan menyasar kelompok prioritas di lokasi prioritas merupakan kunci keberhasilan perbaikan gizi dan tumbuh kembang anak, yang pada akhirnya membantu terhadap pencegahan stunting (Kemenkes RI, 2018).

Gizi kurang menjadi salah satu penyebab stunting sehingga permasalahan ini harus segera diatasi. Gizi kurang pada balita disebabkan oleh beberapa faktor yang kemudian diklasifikasikan sebagai penyebab langsung dan penyebab tidak langsung. Gizi kurang secara langsung disebabkan oleh kurangya konsumsi makanan dan adanya penyakit infeksi. Makin bertambah usia anak maka makin bertambah pula kebutuhannya. Penyebab tidak langsung yaitu ketahanan pangan di keluarga, pola 
pengasuhan anak, serta pelayanan kesehatan dan kesehatan lingkungan (Beal et al., 2018; UNICEF/ WHO, 2013).

Pola pengasuhan anak berpengaruh terhadap pemberian makanan dari orang tua kepada anaknya. Pengasuhan anak dapat berupa sikap dan perilaku ibu atau pengasuhan lain dalam hal kedekatan dengan anak, memberikan makanan, merawat kebersihan memberikan kasih sayang dan sebagainya. Kesemuanya berhubungan dengan keadaan ibu dalam hal kesehatan (fisik dan mental), status gizi, pendidikan, pengetahuan dan keterampilan tentang pengasuhan anak yang buruk, peran dalam keluarga atau masyarakat, sifat pekerjaan, adat kebiasaan keluarga dan masyarakat (Soetjiningsih, 2012).

Kunci penting dalam prinsip gizi seimbang yaitu zat gizi itu sendiri dan prinsip-prinsip utama dalam pemenuhan gizi seimbang yang terdiri dari empat pilar. Pilar pertama yaitu mengkonsumsi makanan yang beragam. Yang dimaksud beranekaragam dalam prinsip ini selain keanekaragaman jenis pangan juga termasuk proporsi makanan yang seimbang, dalam jumlah yang cukup, tidak berlebihan dan dilakukan secara teratur. Pilar kedua yaitu membiasakan perilaku hidup bersih. Kebiasaan hidup berisih ini dimasukkan dalam pilar gizi seimbang karena status gizi seseorang dipengaruhi oleh status kesehatan juga. Pilar ketiga adalah melakukan aktivitas fisik untuk menyeimbangkan input dan output zat gizi terutama energi. Aktivitas fisik dapat meningkatkan metabolisme tubuh, sehingga mengurangi risiko penumpukan zat-zat yang berlebihan di dalam tubuh seperti lemak karena akan cepat dimetabolisme oleh tubuh. Pilar keempat adalah memantau dan mempertahankan berat badan normaluntuk mengetahui sejak dini apabila terdapat kelebihan atau kekurangan berat badan sehingga dapat segera dilakukan intervensi yang tepat dan cepat (Kemenkes RI, 2014).

Dalam keadaan normal, tinggi badan tumbuh bersamaan dengan bertambahnya umur, namun pertambahan tinggi badan relatif kurang sensitif terhadap kurang gizi dalam waktu singkat. Jika terjadi gangguan pertumbuhan tinggi badan pada balita, maka untuk mengejar pertumbuhan tinggi badan optimalnya masih bisa diupayakan, sedangkan anak usia sekolah sampai remaja relatif kecil kemungkinannya. Maka peluang besar untuk mencegah stunting 
dilakukan sedini mungkin dengan mencegah faktor resiko gizi kurang baik pada remaja putri, wanita usia subur (WUS), ibu hamil maupun pada balita. Selain itu, menangani balita yang dengan tinggi dan berat badan rendah yang beresiko terjadi stunting, serta terhadap balita yang telah stunting agar tidak semakin berat (UNICEF Indonesia, 2012).

\section{TUJUAN DAN MANFAAT}

Penyuluhan ini dilaksanakan di TK Aisyiah Pucangan Kartasura karena dari total 60 siswa berusia 4-5 tahun, terdapat 13 anak yang menderita stunting, atau 1 dari 5 anak mengalami stunting di kelompok TK A (usia 4-5 tahun) tersebut.

Upaya penyuluhan ini merupakan salah satu wujud mendukung program pemerintah dalam mencegah stunting. Seperti tertuang dalam Strategi Nasional Komunikasi Perubahan Perilaku Percepatan Pencegahan Stunting yang terdiri dari lima pilar, yaitu: 1) Komitmen dan visi kepemimpinan; 2) Kampanye nasional dan komunikasi perubahan perilaku; 3) Konvergensi program pusat, daerah, dan desa; 4) Ketahanan pangan dan gizi; dan 5) Pemantauan dan evaluasi. Strategi ini diselenggarakan di semua tingkatan pemerintah dengan melibatkan berbagai institusi pemerintah yang terkait dan institusi non-pemerintah seperti swasta, masyarakat madani, dan komunitas (Kemenkes RI, 2018).

Tujuan jangka pendek diadakan penyuluhan tentang makanan sehat adalah uutuk meningkatkan pengetahuan mengenai makanan sehat berigizi dan seimbang kepada ibu dan anak balita.

Tujuan jangka panjang dari penyuluhan ini dalah memberikan bekal kepada ibu yang masih usia reproduktif agar memiliki pengetahuan yang cukup untuk memenuhi gizi yang baik saat hamil, saat menyusui dan memperbaiki gizi balita sehingga dapat menurunkan stunting.

\section{METODE PELAKSANAAN KEGIATAN}

Metode pelaksanaan kegiatan ini adalah dengan presentasi menggunakan power point dan video edukasi.

Sasaran penyuluhan adalah ibu-ibu usia reproduktif (yang merupakan sasaran primer pencegahan stunting), maupun ibu-ibu usia non reproduktif (yang merupakan sasaran skunder yang berpebngaruh terhadap pola asuh daan pemberian makan balita). Populasi sasaran tersebut adalah orangtua anak yang bersekolah di PAUD/ TK Aisyiah Pucangan Kartasura. 
Penelitian untuk mengukur pengetahuan sebelum dan sesudah penyuluhan ini merupakan jenis quasi experimental dengan rancangan penelitian one group pre and post test design. Nilai yang didapatkan kemudian dianalisis dengan uji analisis Paired sample $t$ test dan uji alternatifnya yaitu Wilcoxon menggunakan perangkat lunak SPSS 22.0.

\section{HASIL DAN DISKUSI}

Kegiatan penyuluhan ini telah dilaksanakan pada hari Sabtu tanggal 5 Oktober 2019 di TK Aisyiah Pucangan Kartasura, Sukoharjo, Jawa Tengah.

Kegiatan ini diikuti oleh 41 peserta. Mean/ rerata nilai pretest sebesar 65,12 sedangkan post test sebesar 82,2.

Dari kelompok pretest dan post test yang akan dianalisis kemudian dilakukan uji normalitas data dan didapatkan hasil kelompok pretes dan kelompok postest masing-masing nilai $\mathrm{p}<0,0001$ sehingga data kelompok pretest dan post test tidak berdistribusi normal. Selanjutnya uji yang dilakukan adalah uji non parametric wilcoxon. Dari hasil uji wilcoxon terhadap pengetahuan didapatkan 1 orang yang nilai postestnya turun, dan 36 orang nilainya meningkat dan 4 orang nilainya sama (nilai $\mathrm{p}<0,0001)$.

\section{SIMPULAN DAN SARAN}

Penyuluhan tentang makanan sehat sangat penting dilakukan untuk meningkatkan poengetahuan ibu mengenai makanan sehat, seimbang, bergizi dan beragam sesuai pedoman umum gizi seimbang. Hal ini akan berimplementasi jangka pendek dan jangka panjang dalam menurunkan kejadian stunting balita.

Stunting merupakan masalah yang kompleks yang dimulai sejak awal kehidupan yaitu sejak dalam kandungan. Diperlukan peran pemerintah dalam mendukung penurunan prevalensi stunting.

Kepada pihak pemerintah misalnya departemen kesehatan, departemen sosial, diharapkan dapat meningkatkan kesejahteraan ibu hamil, mengentaskan kemiskinan sehingga bisa memutus rantai stunting. Dengan memberikan sosialisasi nasional terkait kebijakan pemberian nutrisi pada 1000 awal kehidupan, misalnya dengan 
strategi KIE (Komunikasi, Informasi dan

Edukasi).

Kepada ibu dalam lingkup rumah tangga

dan komunitas bisa lebih mengetahui faktor

risiko dan pemahaman mengenai dampak

dan penanggulangan stunting sehingga bisa

meningkatkan pengetahuan dan sikap agar

dapat mengubah perilaku ke arah lebih baik.

\section{UCAPAN TERIMAKASIH}

Penyuluhan ini dilaksanakan atas kerjasama

Departemen Public Health and Family

Medicine/ Kedokteran Keluarga Fakultas

Kedokteran Universitas Muhammadiyah

Surakarta dengan TK Aisyiah Pucangan

Kartasura. Kami ucapkan kepada pihak-pihak

yang telah membantu dalam kegiatan

pengabdian masyarakat ini .

\section{DAFTAR PUSTAKA}

Achadi,, Endang. L. 2015. Masalah Gizi di Indonesia dan Posisinya secara Global. Disampaiakan dalan 'Diseminasi Global Nutrition Report Dalam Rangka Peringatan Hari Gizi Nasional 2015' diselenggarakan oleh Kementerian PPN/Bappena yang diselenggarakandDi Jakarta, 9 Februari 2015.

Beal T, Tumilowicz A, Sutrisna A, Izwardy D, Neufeld LM.2018. A review of child stunting determinants in Indonesia. Matern Child Nutr. Diakses melalui https://www.ncbi.nlm.nih.gov/pubmed/297 70565pada Oktober 2019.
Hoffman, Daniel J. 2014. Growth retardation and metabolic programming:implications and consequences for adult health and disease risk, J Pediatr (Rio J). 2014;90(4):325-328.

Kemenkes RI, 2011. Keputusan Menteri Kesehatan RI tentang standar antropometri penilaian status gizi anak. http:// www.gizi.depkes.go.id. diakses pada Agustus 2019.

2014. Pedoman Gizi Seimbang. Dirjen Bina Gizi dan KIA. Jakarta.

2018. Pedoman strategi komunikasi perubahan perilaku dalam percepatan pencegahan stunting di indonesia. www.kesmas.kemkes.go.id diakses pada Oktober 2019

Ministry of National Development Planning of Indonesia, 2019. https://www.unicef.org/indonesia/sites/unice f.org.indonesia/files/2019-

07/ROADMAP.pdf. Diakses pada September 2019.

Riskesdas. 2013. Riset Kesehatan Dasar 2013. Jakarta: Badan Penelitian Dan Pengembangan Kesehatan Kementerian Kesehatan RI. Diakses melalui http://www.depkes.go.id/resources/download/general/H asil\%20Riskesdas\%202013.pdf pada Agustus 2019.

$\begin{array}{rrr}2018 . & \text { Hasil } & \text { Utama } \\ \text { Riskesdas2018. } & \text { Diakses } & \text { melalui }\end{array}$ https://www.litbang.kemkes.go.id/hasil-utamariskesdas-2018/,pada Agustus 2019.

Soetjiningsih. 2012. Faktor-faktor yang Mempengaruhi Tumbuh Kembang dalam Tumbuh Kembang Anak Edisi Kedua. Soetjiningsih dan Gde Ranuh (editor). Jakarta: Penerbit Buku Kedokteran EGC UNICEF Indonesia. 2012. Ringkasan Kajian Kesehatan Unicef Indonesia. Diakses melalui http://www.unicef.org/indonesia/id/ pada Agustus 2019. 
UNICEF Indonesia. 2012. Ringkasan Kajian Kesehatan Unicef Indonesia. Diakses melalui http://www.unicef.org pada Agustus 2019.
UNICEF/WHO. 2013. Improving Child Nutrition The Achievable Imperative For Global Progress. UNICEF: New York. Diakses melalui http://reliefwebint/sites/reliefweb.int-

/files/resources/Improving 